\title{
Asymmetric Vinylogous Mukaiyama-Michael Reaction via Iminium Catalysis
}

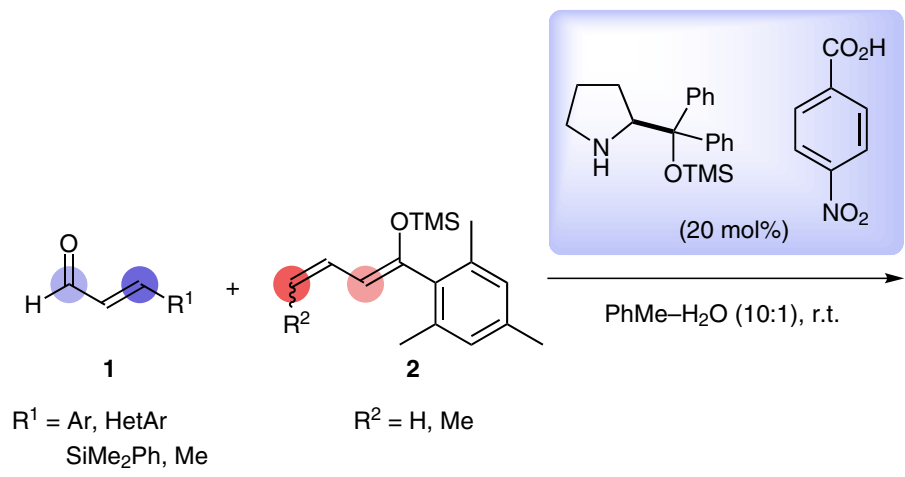

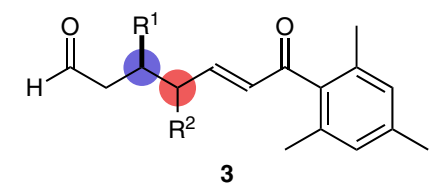

22 examples

up to $90 \%$ yield er up to $99.5: 0.5$

Selected examples:<smiles>Cc1cc(C)c(C(=O)/C=C/CC(CC=O)c2ccccc2)c(C)c1</smiles>

$74 \%$ yield, er $=99.5: 0.5$<smiles>Cc1cc(C)c(C(=O)/C=C/CC(C)CC=O)c(C)c1</smiles>

$50 \%$ yield, er $=85.5: 14.5$<smiles>Cc1cc(C)c(C(=O)/C=C/CC(CC=O)c2cccs2)c(C)c1</smiles>

$72 \%$ yield, er $=99.5: 0.5$<smiles>Cc1cc(C)c(C(=O)/C=C/[C@H](C)C(CC(=O)c2ccccc2)c2ccccc2)c(C)c1</smiles>

$77 \%$ yield, $\mathrm{dr}=92: 8$ $\mathrm{er}=99.5: 05$ from $3 Z-2$<smiles>Cc1cc(C)c(C(=O)/C=C/CC(CC=O)Cc2ccccc2)c(C)c1</smiles>

$90 \%$ yield, er > 99.5:0.5<smiles>Cc1cc(C)c(C(=O)/C=C/C(C)C(CC=O)c2ccccc2)c(C)c1</smiles>

$65 \%$ yield, $d r=77: 23$ er $=98: 2$ from $3 E-2$ in ethanol
Significance: The authors report a highly enantioand diastereoselective vinylogous MukaiyamaMichael reaction of acylic dienol silyl ethers 2 to various enals $\mathbf{1}$ by employing a Jørgensen-Hayashi catalyst. 1,7-Dicarbonyl compounds $\mathbf{3}$ are obtained under mild reaction conditions with good to excellent yield and remarkable regioselectivity. Z/E-Configured $\gamma$-methyl-substituted dienol silyl ethers are selectively converted into the anti and syn products $\mathbf{3}$ with excellent enantioselectivity.

\section{Gategory}

Organo- and Biocatalysis

\section{Key words}

vinylogous Mukaiyama-Michael reaction

Jørgensen-Hayashi catalyst

enals

dienol silyl ethers
Comment: Vinylogous Michael reactions of dienol derivatives can form a $\mathrm{C}-\mathrm{C}$ bond with high regioand stereoselectivity in the presence of a chiral catalyst. However, a catalytic enantioselective process of this reaction with acyclic nucleophiles and enals was elusive since the reaction can produce a number of regio- and stereoisomers. Herein, the catalyst nicely operates presumably by forming an imminium species with enal $\mathbf{1}$ to induce 1,4-addition of nucleophile 2 with high $\gamma$-selectivity. 